\title{
[OP.5C.05] SERUM URIC ACID IS INCREASED IN NORMOTENSIVE OBESE CHILDREN WITH A PARENTAL HYSTORY OF HYPERTENSION.
}

Mule\&\#8217;, G.; Castiglia, A.; Genco, M.; Consiglio, E.; Cusimano, C.; Geraci, G.; Morreale, M.; Roppolo, R.; Cardella, F.; Cottone, S.; Guarino, L.

Journal of Hypertension: September 2017

doi: 10.1097/01.hjh.0000523113.14879.2f

ORAL SESSION 5C: PEDIATRIC HYPERTENSION: PDF Only

\begin{abstract}
Objective: Increased uric acid levels are closely associated with new-onset hypertension in children, and pilot studies showed that pharmacological lowering of uric acid may reduce blood pressure (BP) in obese pediatric patients. Nevertheless, controversy remains concerning a direct causative role of serum uric acid (SUA) in the pathogenesis of essential hypertension (EH).

Our study was aimed to determine if normotensive obese children and adolescent offspring of adults with EH show SUA levels different than those of pediatric subjects in whom there is non family history of EH.

Design and method: Fifty-nine obese normotensive children and adolescents, attending for metabolic assessment the Pediatric Diabetes Unit, Children's Hospital "G. Di Cristina", and for cardiovascular evaluation the ESH Hypertension excellence center of the University of Palermo, were studied. All the subjects, aged between 8 and 17 years, underwent routine blood chemistry and oral glucose tolerance test with glucose and insulin determinations.
\end{abstract}

All subjects had blood pressure determinations below the 9oth percentile and had no previous history of elevated blood pressure.

Results: There were 14 subjects whose parents were both normotensive (FH-), and the remaining 45 subjects whose one or both parents were hypertensive.

$\mathrm{FH}+$ did not differ regarding age, sex distribution, blood pressure values, body mass index, waist circumference, serum glucose levels when compared to FH-. Among the metabolic parameters assessed, only SUA was significantly higher in $\mathrm{FH}+$ than in $\mathrm{FH}$ - ( $\mathrm{p}=0.007$; figure 1$)$.

Copyright (C) 2017 Wolters Kluwer Health, Inc. All rights reserved. 